\title{
Interfacial Polycondensation Synthesis of Optically Sensitive Polyurea Microcapsule
}

\author{
Weidong Lai, ${ }^{1}$ Xinzheng Li, ${ }^{2}$ Huiqing Liu, ${ }^{1}$ Lu Han, ${ }^{1}$ Yajun Zhao, ${ }^{1}$ and Xiaowei Li ${ }^{1}$ \\ ${ }^{1}$ Hebei Key Lab of Optic-Electronic Information and Materials, College of Physics Science and Technology, Hebei University, \\ Baoding, Hebei 071002, China \\ ${ }^{2}$ Department of Sciences, Hebei University of Science and Technology, Shijiazhuang, Hebei 050018, China
}

Correspondence should be addressed to Weidong Lai; laiwd@hbu.edu.cn

Received 19 October 2014; Accepted 21 November 2014; Published 10 December 2014

Academic Editor: Eri Yoshida

Copyright (C) 2014 Weidong Lai et al. This is an open access article distributed under the Creative Commons Attribution License, which permits unrestricted use, distribution, and reproduction in any medium, provided the original work is properly cited.

\begin{abstract}
TMPTA prepolymer resin and photoinitiators of ITX/TPO had been encapsulated in core-shell structured microcapsules as optical responding ingredients based on interfacial polycondensation method, and polyurea structured microcapsule shell had been formed on the sheared $\mathrm{O} / \mathrm{W}$ interface. The synthesized microcapsule had regular core-shell structure with the diameter of about $0.455 \mu \mathrm{m}$ and shell thickness of about $40 \mathrm{~nm}$. UV-visible absorption spectra indicated that the encapsulated ITX and TPO photoinitiators could efficiently absorb UV irradiation. Under exposure, the $\mathrm{C}=\mathrm{C}$ bonds absorbance of the microencapsulated TMPTA decreased rapidly and then nearly unchanged during further exposure after $30 \mathrm{~s}$. This implied that the optical response was achieved by $\mathrm{C}=\mathrm{C}$ bond cleavage of TMPTA monomer initiated by the photoinitiator radicals, to form network polymers in microcapsules. The relative crosslinking rate was about $50 \%$. Due to core polymer formation, the thermal phase change temperature of exposed microcapsules was narrowed and ranged from 105 to $205^{\circ} \mathrm{C}$, compared with that from 125 to $260^{\circ} \mathrm{C}$ of unexposed microcapsules. Furthermore, the image density decrease at longer irradiation time had also verified the optical responding function of the synthesized microcapsules in macroscopic viewpoint.
\end{abstract}

\section{Introduction}

Microcapsule material has drawn extensive attentions from the viewpoint of fundamental scientific and practical applications $[1,2]$. The precise fabrication of microcapsules has been investigated in Weitz group [3,4]. Microcapsules with different functions have been produced for practical applications in medicine, biotechnology, and industry and for solving environment problems, where $\mathrm{PH}$, temperature, or pressure stimuli are loaded on the microcapsules [5]. The controlled release microcapsules have been synthesized for their obvious utilization in targeting pharmacy [6-8]. The bioartificial application is attempted by encapsulating insulin in semipermeable aqueous membrane in order to substitute the kidney cells [9]. The energy storage microcapsules are also synthesized based on the phase change character of the core compounds, in order to absorb, store, and release large amounts of latent heat at defined temperature range $[10,11]$.

Functional control of these microcapsules can be based either on variation of shell chemical composition or on modification of core ingredients [12]. The distinctive negative temperature-sensitive release has been realized by grafted poly(N-isopropylacrylamide) (PNIPAM) chains into microcapsule surface pores [13]. Recently, microcapsules have been applied in electric ink (E-ink) technique, which is realized by electrically controlling the electrophoresis directions of the color granules in microcapsule core [14]. Photochromic microcapsule has been synthesized by Sawada and Urakawa, and photoacid can be generated in microcapsules under light exposure [15]. Self-healing microcapsule is realized through mechanically cracking the microcapsule shell to allow the core ingredients to stream out and adhere to the deformation or fracture in buildings [16]. Such idea is also utilized to achieve photodegradation function by microencapsulation [17].

Though the temperature-sensitive microcapsules have been intensively researched, the optically sensitive microcapsules have drawn few attentions. In this paper, the interfacial polycondensation method is applied to encapsulate 


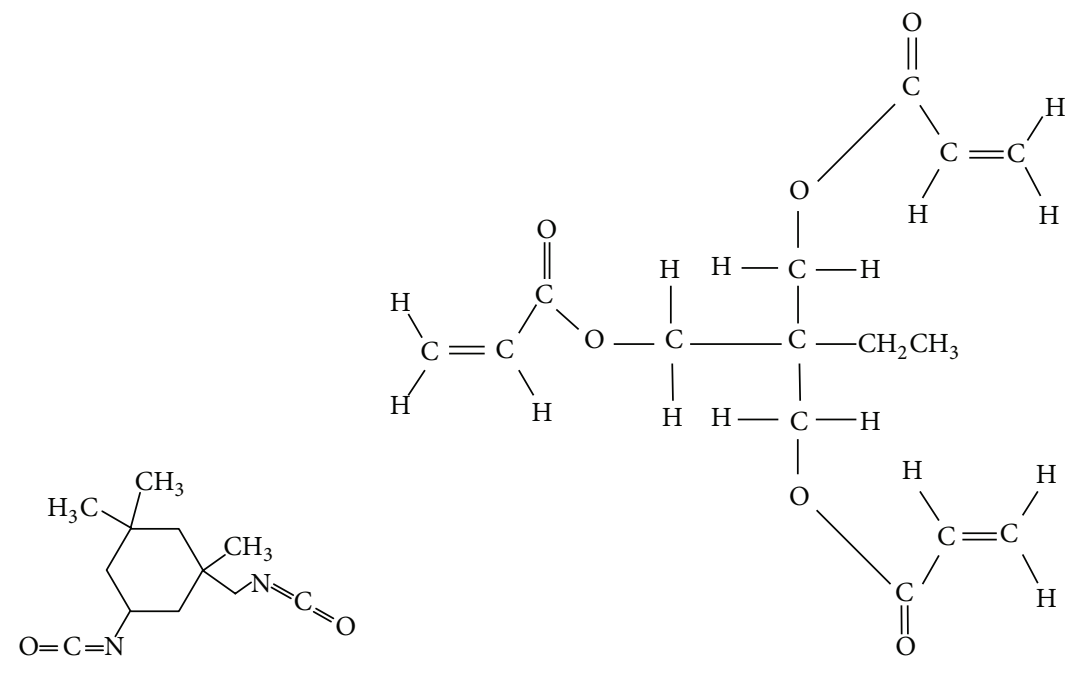

(a)

(b)

FIgURE 1: Molecular structure of (a) IPDI and (b) TMPTA.

the optically sensitive compounds in submicrometer scale. The shell formation process and the morphology of the synthesized microcapsules are monitored. The optical response function is focused on.

\section{Materials and Methods}

2.1. Materials. The microcapsule shell forming raw material is IPDI (3-isocyanatomethyl-3,5,5-trimethylcyclohexyl isocyanate, Bayer, $30 \mathrm{~g}$ ). The photosensitive system is consisted of photocrosslinkable prepolymer resin of TMPTA (trimethylolpropane triacrylate, Sanmu, $20 \mathrm{~g}$ ) with photoinitiators of TPO (diphenyl(2,4,6-trimethylbenzoyl)phosphine oxide, IHT, 1g) and ITX (2-isopropylthioxanthone, IHT, $1 \mathrm{~g})$. Such materials are mixed together and dissolved to generate the oil phase. ODB-2 (2-anilino-6-dibutylamino-3methylfluoran, Shouguang Fukang Corp., 2 g) can be mixed with the oil phase as thermal color-forming ingredient. PVA224 (Kuraray, $4.5 \mathrm{wt} \%$ in deionized water, $150 \mathrm{~mL}$ ) forms water phase.

In Figure 1, the molecular structures of IPDI and TMPTA are present. The IPDI bears two - NCO isocyanate bonds. For TMPTA molecule, there are three $\mathrm{C}=\mathrm{C}$ bonds at its terminals.

2.2. Microcapsule Synthesis and Characterization. The O/W phases are mixed together and sheared at high velocity of $6000 \mathrm{rpm}$ for $10 \mathrm{~min}$. The tetraethylenepentamine (TEPA, $25 \mathrm{wt} \%, 20 \mathrm{~mL}$ ) is injected, and the interfacial polycondensation reaction is carried out by further shearing the emulsion at $800 \mathrm{rpm}$ and lasted for $3 \mathrm{~h}$ at $50^{\circ} \mathrm{C}$. After centrifuging and washing, the microcapsules are dried for further usage.

The shell formation process is monitored by BRUKER Tensor27 Fourier transform infrared (FT-IR) spectrometer. Diameter distribution and structure of the microcapsules are, respectively, characterized by Mastersizer 2000E laser particle size analyzer (Malvern) and TEM (H-800, Hitachi). Thermogravimetric analysis (TGA) and differential thermal

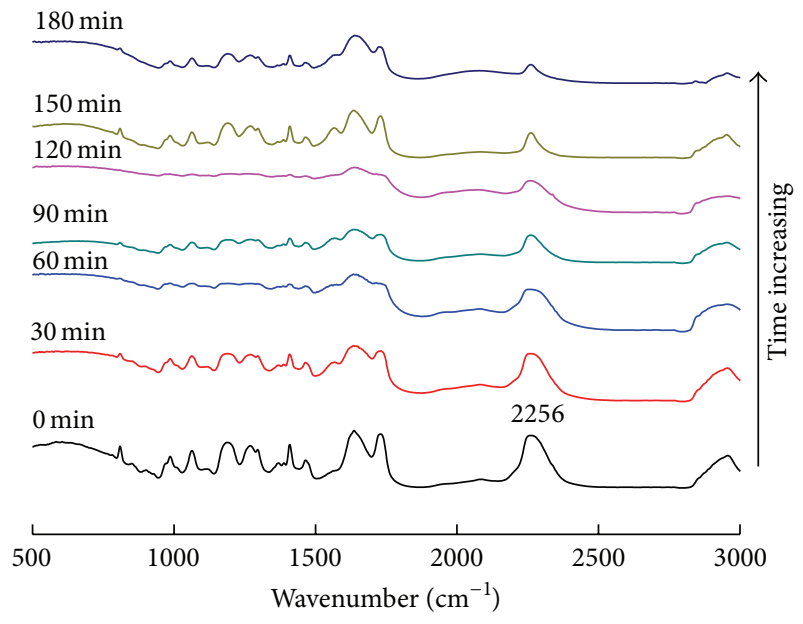

FIGURE 2: FT-IR spectra variance of the emulsions when emulsification time increased.

analysis (DTA) are obtained by thermal analyzer (SDT-Q600, TA).

For the optical responding function, it is observed by two procedures. One is carried out through FT-IR spectra monitoring on the characteristic bond absorbance of microcapsules under exposure from high pressure mercury lamp. The other is the color image density detection by X-Rite 504 spectrodensitometer after the microcapsule emulsion is mixed with D-8 (4-Hydroxy-4\&apos;-isopropoxydiphenylsulfone, Shouguang Fukang Corp., $4 \mathrm{~g}$ ) and coated on cellulose acetate film with the coating thickness of $12 \mu \mathrm{m}$. The dried film is first exposed by high pressure mercury lamp to achieve optical response and then thermally developed to form coloration.

\section{Results and Discussion}

3.1. Microcapsule Forming Process. During O/W (oil/water phase) emulsification process, the emulsion is sampled and 


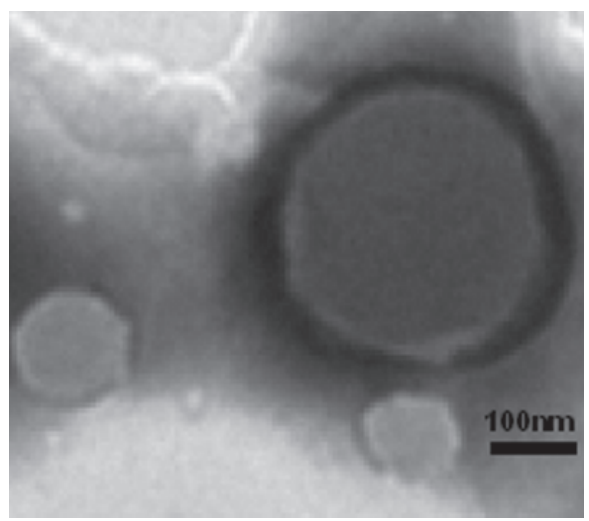

(a)

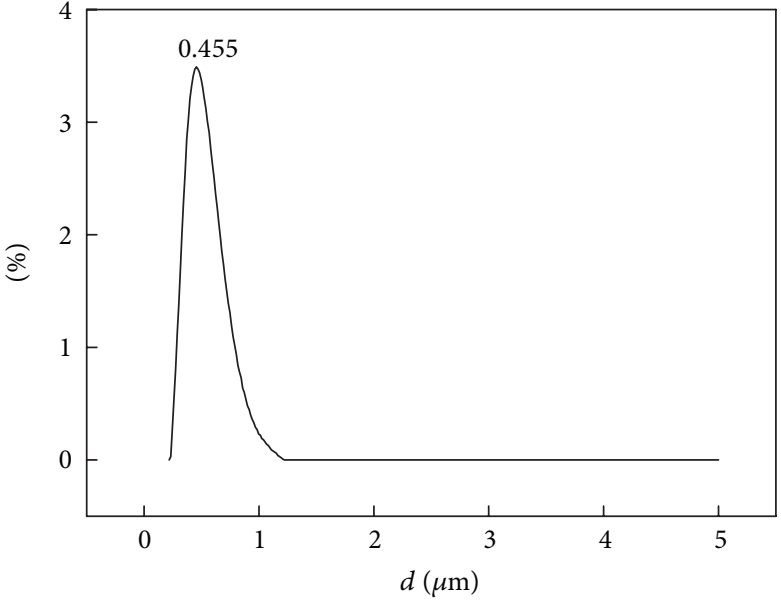

(b)

FIGURE 3: (a) TEM graph and (b) diameter distribution of the synthesized microcapsules.

monitored through FT-IR spectra as shown in Figure 2. The absorbance at $2256 \mathrm{~cm}^{-1}$ has been decreased when reaction time increased.

Such absorbance at $2256 \mathrm{~cm}^{-1}$ is related to the characteristic absorption of -NCO isocyanate bonds, which are the terminal groups of the IPDI molecule as shown in Figure 1. The absorbance of -NCO spectra at $2256 \mathrm{~cm}^{-1}$ in Figure 2 decreases when the reaction time increases, which means that the $-\mathrm{NCO}$ bonds of IPDI have been gradually consumed during the emulsification reaction. The -NCO bonds of IPDI are crosslinked by the $-\mathrm{NH}_{2}$ amino bonds of TEPA molecules to form polyurea polymer at the O/W interface. After $180 \mathrm{~min}$, such interfacial polycondensation process has nearly been completed since the absorption peak of -NCO bonds almost disappears. The polyurea structured microcapsule shell is generated.

3.2. Morphology of the Microcapsules. The TEM graph of the synthesized microcapsules is shown in Figure 3(a). Regular core-shell structure appeared. The shell is compact, and its thickness is about $40 \mathrm{~nm}$. The thickness distribution is nearly unchanged around the microcapsule. It means that the shell formation reaction is isotropically carried out. Also, it should be noticed that other microcapsules with different size appeared.

The microcapsule diameter distribution is detected in Figure 3(b). Most of the microcapsules are synthesized with the size around $0.455 \mu \mathrm{m}$. The diameter distribution half-width is about $0.38 \mu \mathrm{m}$. Such narrow size distribution is a benefit for achieving precisely controllable optical responding function.

3.3. Absorption Spectra of the Microcapsules. In Figure 4(a), the UV-visible absorption spectrum of the microcapsules coated on film is present. There has been a high absorption peak at UV band, which is ascribed to the absorption of microcapsule shell, the photoinitiators, and the cellulose acetate coating film. The most important feature in Figure 4(a) is that the absorption peaks appeared at the wavelengths of 368 and $384 \mathrm{~nm}$. Such absorption is evaluated and discriminated as the absorption peaks of photoinitiators ITX and TPO based on their absorption spectra in Figure 4(b).

This implies that the ITX and TPO photoinitiators have been successfully encapsulated and have distinct optical absorption at the wavelength range from 368 to $384 \mathrm{~nm}$. It also should be noticed that such absorption band is similar to the absorption of TPO rather than ITX. TPO photoinitiator is more efficient for absorbing exposure energy.

3.4. $C=C$ Crosslinking Process in Microcapsules. In Figure 5, $\mathrm{C}=\mathrm{C}$ bonds characteristic absorption at $1635 \mathrm{~cm}^{-1}$ of TMPTA monomer has appeared in the FT-IR spectra of the microcapsules. This implies that TMPTA monomer has been encapsulated. Such $\mathrm{C}=\mathrm{C}$ bonds are at the terminal positions of the TMPTA molecules as shown in Figure 1.

Then photocrosslinking reaction is expected to be performed between TMPTA molecules initiated by the photoinitiators of ITX and TPO in microcapsules. Since such reaction cannot be observed and detected directly, the FT-IR spectra of $\mathrm{C}=\mathrm{C}$ characteristic bonds at $1635 \mathrm{~cm}^{-1}$, which are involved in the crosslinking reactions, are monitored. After exposing at different time, the $\mathrm{C}=\mathrm{C}$ absorbance variance of microcapsules is shown in Figure 6.

Since the $\mathrm{C}=\mathrm{C}$ bonds concentration is proportional to the area around $1635 \mathrm{~cm}^{-1}$ absorption peak, the crosslinking rate in microcapsule is calculated as

$$
\eta=\frac{A_{0}-A_{t}}{A_{0}} \times 100 \%,
$$

in which the $A_{t}$ is the $\mathrm{C}=\mathrm{C}$ bonds absorption area at the $t$ exposure time and $A_{0}$ is the initial area.

The photocrosslinking process in microcapsule is present in Figure 7. With exposure time increased, the 


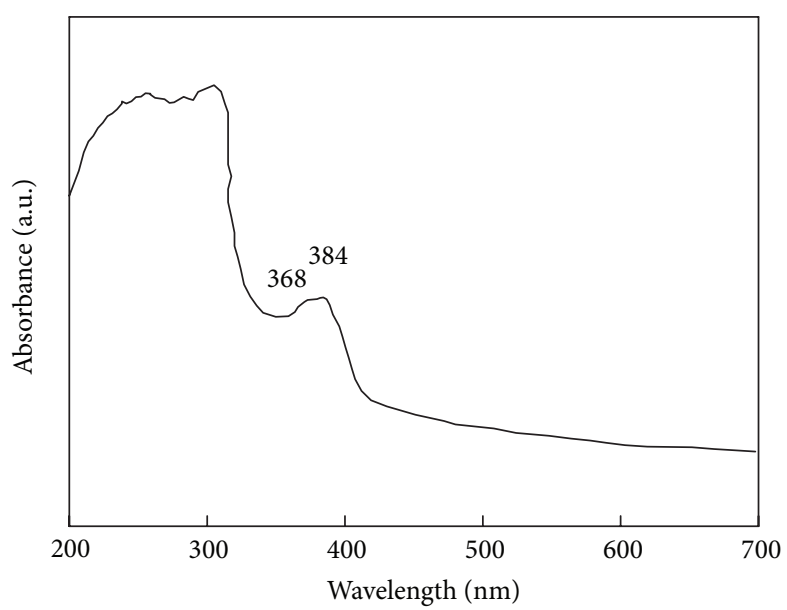

(a)

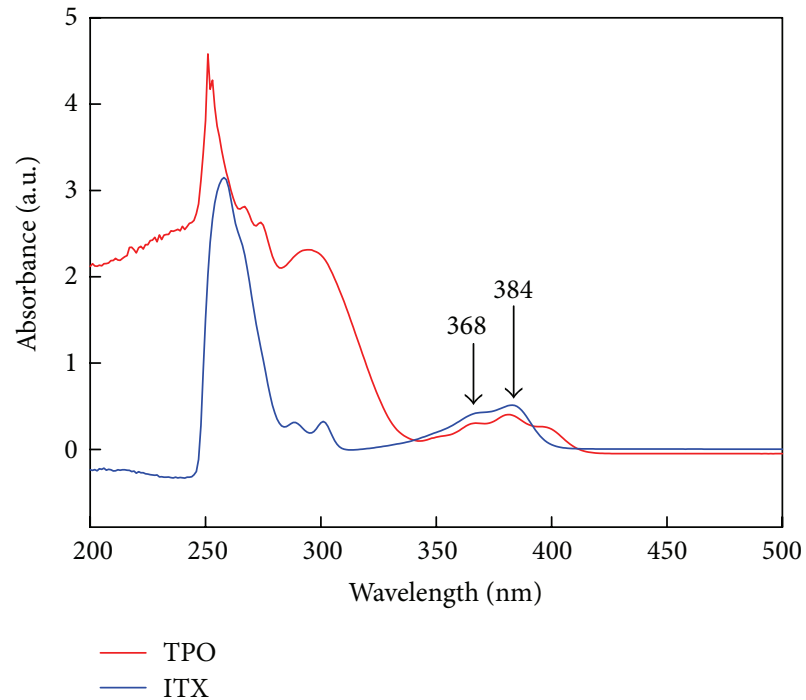

(b)

FIGURE 4: Absorption spectra of (a) microcapsules and (b) photoinitiators TPO and ITX.

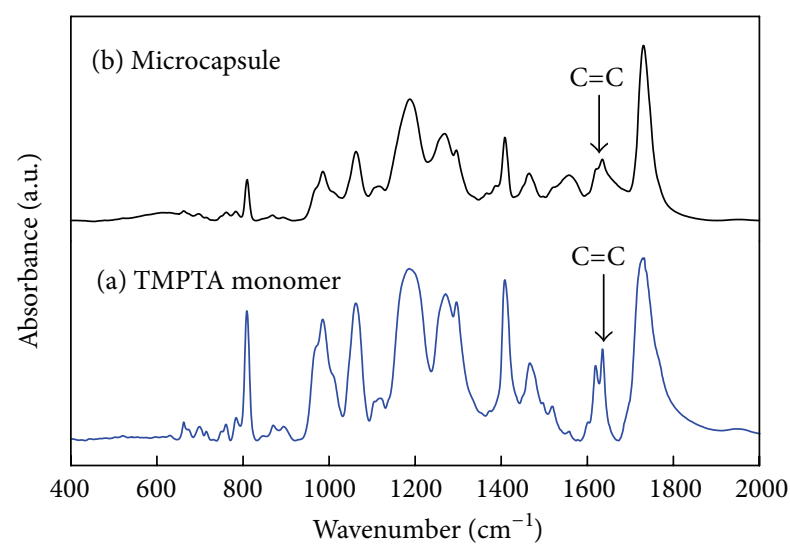

FIgURE 5: The FT-IR absorption spectra of (a) TMPTA monomer and (b) the microcapsule.

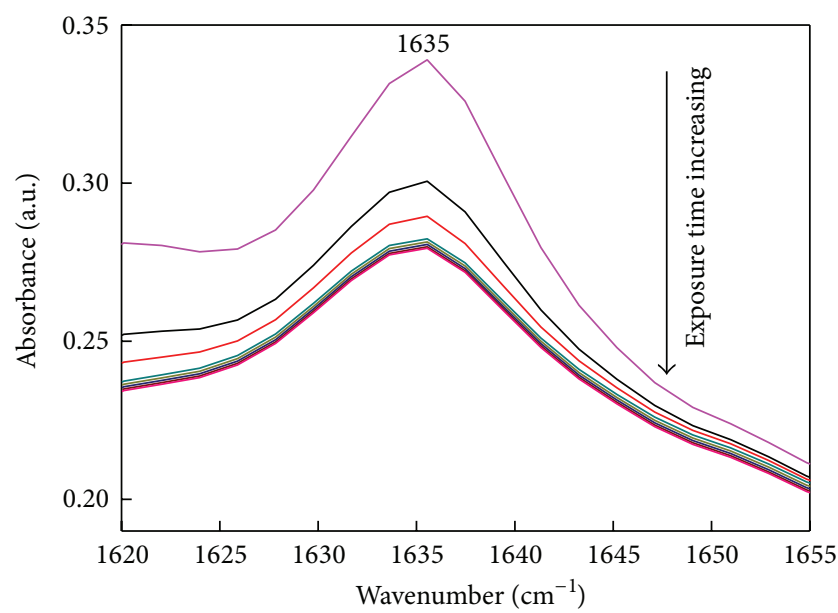

FIgURE 6: The absorbance variance at $1635 \mathrm{~cm}^{-1}$ of the microcapsules under exposure.

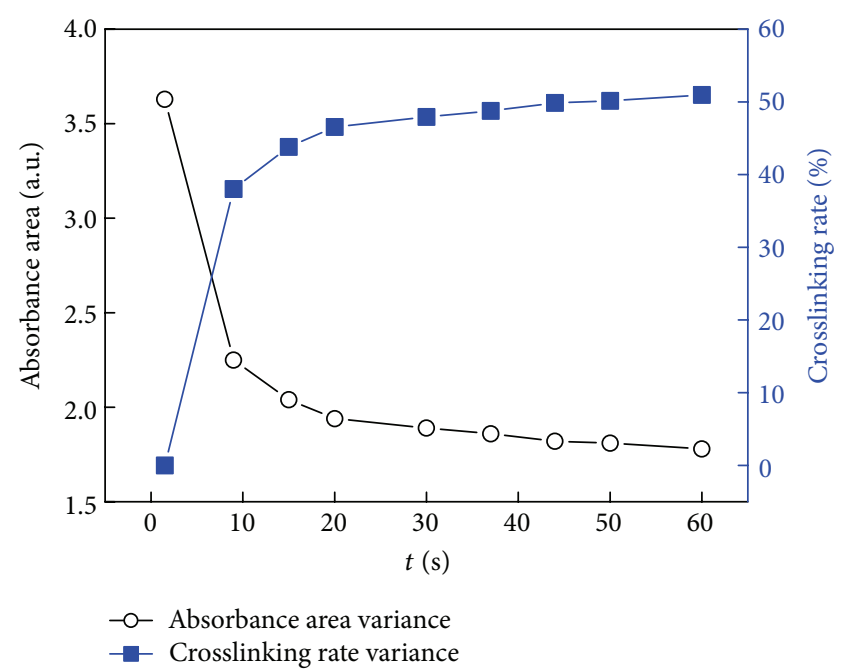

FIGURE 7: The $\mathrm{C}=\mathrm{C}$ absorbance area and the calculated crosslinking rate in microcapsule under exposure.

photocrosslinking reaction of TMPTA molecules is fast initiated by the radicals sourced from photoinitiators of ITX and $\mathrm{TPO}$, and there is a distinct decrease of $\mathrm{C}=\mathrm{C}$ absorbance at the initial exposing time combined with a fast increment of crosslinking rate. Such a phenomenon is ascribed to the reason that the concentration and diffusion activity of the photoinitiator radicals are higher in microcapsule at initial exposing time and can induce efficient crosslinking between $\mathrm{C}=\mathrm{C}$ bonds of TMPTA molecules.

Under longer exposure time, the consumption of photoinitiators has been heightened, and the crosslinked polymer network also restricts the diffusion of the radicals. Consequently, the crosslinking rate is slowly varied after further 

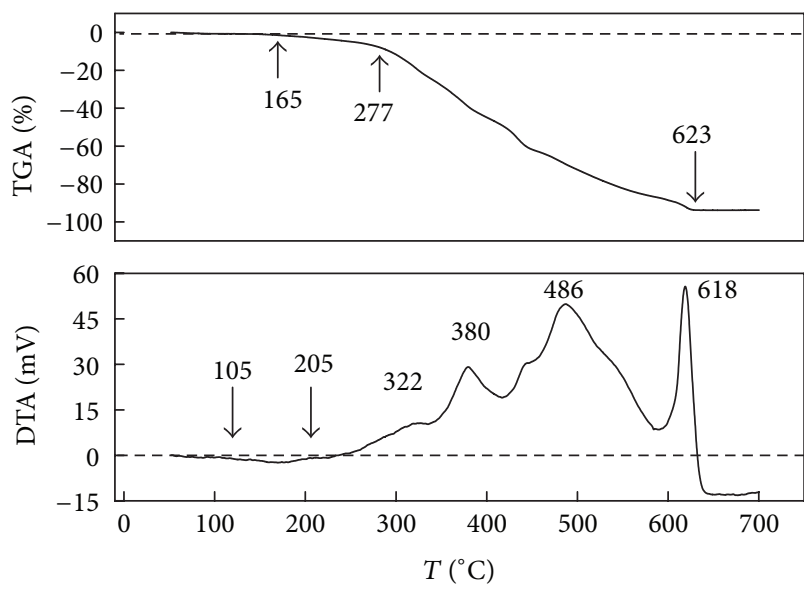

(a)
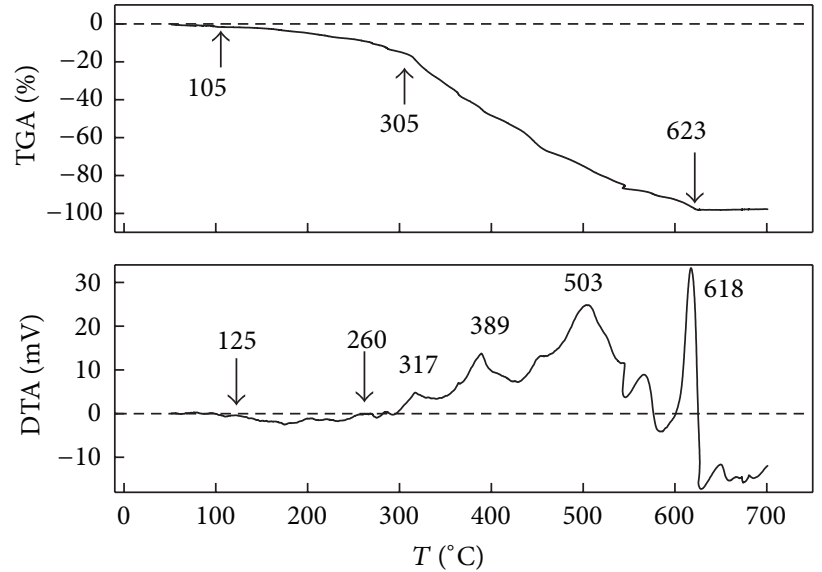

(b)

FIgURE 8: TGA and DTA thermograms of (a) the exposed microcapsule and (b) the unexposed microcapsule, at heating rate of $10^{\circ} \mathrm{C} / \mathrm{min}$.

exposure above $30 \mathrm{~s}$ in Figure 7. The maximal crosslinking extent in microcapsules is about $50 \%$. It is reasonably deduced that there have been solid polymer and liquid TMPTA resin comixed in microcapsules after exposure. The optical responding function has been achieved.

3.5. Thermal Analysis of the Microcapsules. Optical exposure has changed the core ingredients from liquid monomer state to network polymers. The thermal properties would be affected by such state transition before and after exposure. In Figure 8, TGA and DTA thermograms of the exposed and unexposed microcapsules are obtained.

After exposure, the initial weight loss of the microcapsules is from $165^{\circ} \mathrm{C}$ followed by a slow losing trend, and then rapid loss appears from $277^{\circ} \mathrm{C}$ and ended at $623^{\circ} \mathrm{C}$ in Figure 8(a). Compared with TGA of unexposed microcapsule in Figure $8(\mathrm{~b})$, the remarkable weight loss temperature is reduced with the magnitude of $28^{\circ} \mathrm{C}$ after exposure. When it comes to DTA analysis, the phase change temperature of the exposed microcapsule is ranged from 105 to $205^{\circ} \mathrm{C}$ before remarkable weight loss, which is also different compared with the phase change temperature from 125 to $260^{\circ} \mathrm{C}$ of unexposed sample in Figure 8(b).

Such a variance is ascribed to the polymer network formation in microcapsule core, and the structure of microcapsule shell may be also affected by polymer bonds grafting on shell surface after exposure. In DTA curve, the heat absorption peaks at 322,380 , and $486^{\circ} \mathrm{C}$ of exposed microcapsules are, respectively, corresponding to the peaks at 317,389 , and $503^{\circ} \mathrm{C}$ of unexposed microcapsules. UV exposure has affected the chemical and physical structures of microcapsules.

3.6. Optical-Thermal Color Forming Density Property of Microcapsule. In order to directly evaluate the opticalresponding character of the synthesized microcapsules, the ODB-2 dye molecules are added into the core ingredients. The D-8 dyes acted as color-formation developer and are dispersed outside the microcapsules and coated on films.

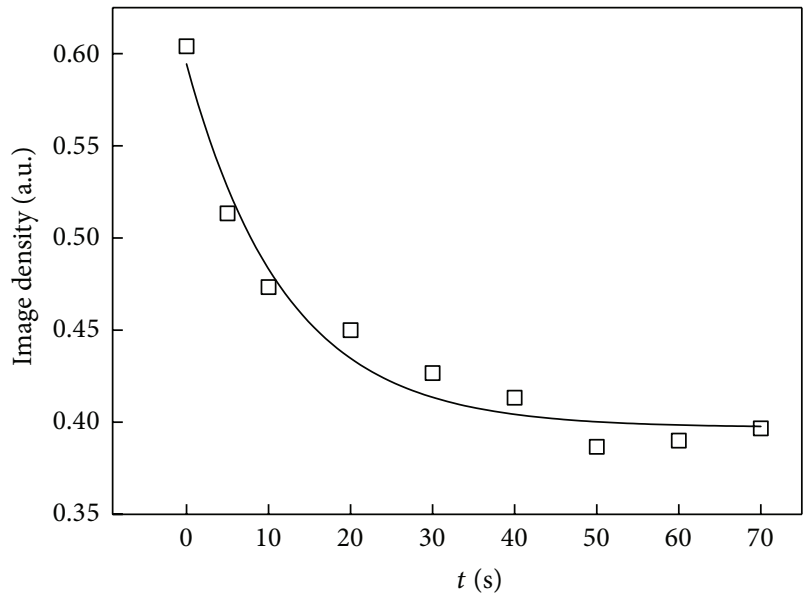

FIGURE 9: Image density variance of the microcapsules exposed at different time and then thermally processed at $150^{\circ} \mathrm{C}$.

After exposure, the film is thermally developed at $150^{\circ} \mathrm{C}$, since such temperature is corresponding to remarkable phase change of the microcapsule shell according to Figures 8(a) and $8(\mathrm{~b})$ as the TGA and DTA thermograms of the exposed and unexposed microcapsule. The film changes its color from white to black.

The color image density is detected and shown in Figure 9. The initial image density without exposure is about 0.62 . It means that the $\mathrm{D}-8$ molecules have penetrated through the phase changed microcapsule shell and efficiently reacted with the ODB-2 to form black color at $150^{\circ} \mathrm{C}$.

With exposure time increased, the image density is decreased. Such a variance is ascribed to the polymer network generation in microcapsule through $\mathrm{C}=\mathrm{C}$ photocrosslinking reactions, which has confined and restricted the ODB-2 molecules into the polymers. The further color-forming reaction between ODB- 2 and the penetrated D-8 is consequently attenuated. As a result, the longer the exposure time is, the less the ODB-2 participates in the color-forming reaction. 
The image density consequently decreases at a monotonic trend. Since the crosslinking extent in the microcapsule is increased slowly after $30 \mathrm{~s}$ as shown in Figure 7, the image density is also decreased slowly after $30 \mathrm{~s}$ exposure time.

Such image density variance has verified the opticalresponding function of the synthesized microcapsules in macroscopic viewpoint.

\section{Conclusion}

In this paper, the interfacial polycondensation method is utilized to synthesize core-shell microcapsules with opticalresponding function. The polyurea shelled microcapsule has been obtained, which is generated by polycondensation between $-\mathrm{NCO}$ bonds of isocyanate IPDI and the $-\mathrm{NH}_{2}$ end groups of TEPA molecules. Shell formation reaction is finished after TEPA was added for $180 \mathrm{~min}$. The microcapsule diameter is about $0.455 \mu \mathrm{m}$ and the shell has thickness of about $40 \mathrm{~nm}$. The photoinitiators of ITX and TPO as well as the prepolymer TMPTA have been encapsulated, which is verified by UV-visible or FT-IR absorption spectra. The $\mathrm{C}=\mathrm{C}$ crosslinking reaction has been carried out among TMPTA molecules initiated by the radicals sourced from photoinitiators of ITX and TPO after exposure. The maximal photocrosslinking extent is calculated as about 50\%. Due to the polymer network generated in microcapsules, the microcapsule chemical and physical structures have been affected. Thermal analysis results combined with the image density decreasing variance have verified such optically induced change in the synthesized microcapsules. The optically sensitive microcapsules have potential application in cosmetics, pharmacy, optical information recording, or even insecticide fields.

\section{Conflict of Interests}

The authors declare that there is no conflict of interests regarding the publication of this paper.

\section{Acknowledgments}

This work is financially supported by Specialized Research Fund for the Doctoral Program of Higher Education (20101301120002), International Foundation for Science (C4690-1), and Natural Science Foundation of Hebei Province (F2011201103).

\section{References}

[1] S. Sadasivan, K. Köhler, and G. B. Sukhornkov, "Fabrication of organized porphyrin-nanotube-attached heat-sensitive polyelectrolyte capsules," Advanced Functional Materials, vol. 16, no. 16, pp. 2083-2088, 2006.

[2] S.-H. Kim and B. Kim, "Controlled formation of doubleemulsion drops in sudden expansion channels," Journal of Colloid and Interface Science, vol. 415, pp. 26-31, 2014.

[3] D. Lee and D. A. Weitz, "Double emulsion-templated nanoparticle colloidosomes with selective permeability," Advanced Materials, vol. 20, no. 18, pp. 3498-3503, 2008.
[4] A. Abbaspourrad, S. S. Datta, and D. A. Weitz, "Controlling release from $\mathrm{pH}$-responsive microcapsules," Langmuir, vol. 29, no. 41, pp. 12697-12702, 2013.

[5] R. Arshady and B. Boh, Microcapsule Patents and Products, Citus Books, London, UK, 2003.

[6] L. F. Oliveira, J. Marques, P. J. G. Coutinho, P. Parpot, and C. J. Tavares, "Photocatalytic thin films coupled with polymeric microcapsules for the controlled-release of volatile agents upon solar activation," Journal of Physics: Conference Series, vol. 439, no. 1, Article ID 012018, 2013.

[7] A. M. Dilauro, A. Abbaspourrad, D. A. Weitz, and S. T. Phillips, "Stimuli-responsive core-shell microcapsules with tunable rates of release by using a depolymerizable poly(phthalaldehyde) membrane," Macromolecules, vol. 46, no. 9, pp. 3309-3313, 2013.

[8] O. Kreft, A. M. Javier, G. B. Sukhorukov, and W. J. Parak, "Polymer microcapsules as mobile local pH-sensors," Journal of Materials Chemistry, vol. 17, no. 42, pp. 4471-4476, 2007.

[9] K. Yoshida, Y. Hasebe, S. Takahashi, K. Sato, and J.-I. Anzai, "Layer-by-layer deposited nano- and micro-assemblies for insulin delivery: a review," Materials Science and Engineering C, vol. 34, no. 1, pp. 384-392, 2014.

[10] A. M. Borreguero, J. F. Rodríguez, J. L. Valverde, T. Peijs, and M. Carmona, "Characterization of rigid polyurethane foams containing microencapsulted phase change materials: microcapsules type effect," Journal of Applied Polymer Science, vol. 128, no. 1, pp. 582-590, 2013.

[11] V. V. Tyagi, S. C. Kaushik, S. K. Tyagi, and T. Akiyama, "Development of phase change materials based microencapsulated technology for buildings: a review," Renewable and Sustainable Energy Reviews, vol. 15, no. 2, pp. 1373-1391, 2011.

[12] L. Y. Chu, T. Yamaguchi, and S. Nakao, "A molecularrecognition microcapsule for environmental stimuli-responsive controlled release," Advanced Materials, vol. 14, pp. 386-389, 2002.

[13] M.-J. Zhang, W. Wang, R. Xie et al., "Microfluidic fabrication of monodisperse microcapsules for glucose-response at physiological temperature," Soft Matter, vol. 9, no. 16, pp. 4150-4159, 2013.

[14] Y. Chen, J. Au, P. Kazlas, A. Ritenour, H. Gates, and M. McCreary, "Electronic paper: flexible active-matrix electronic ink display," Nature, vol. 423, no. 6936, p. 136, 2003.

[15] K. Sawada and H. Urakawa, "Preparation of photosensitive color-producing microcapsules utilizing in situ polymerization method," Dyes and Pigments, vol. 65, no. 1, pp. 45-49, 2005.

[16] J. Lee, D. Bhattacharyya, M. Q. Zhang, and Y. C. Yuan, "Fracture behaviour of a self-healing microcapsule-loaded epoxy system," Express Polymer Letters, vol. 5, no. 3, pp. 246-253, 2011.

[17] F. Yu, Y. Liu, and S. Yao, "A new method to synthesize microcapsule and its application in controllable photodegradation of polymers," Polymer Journal, vol. 34, no. 4, pp. 302-305, 2002. 

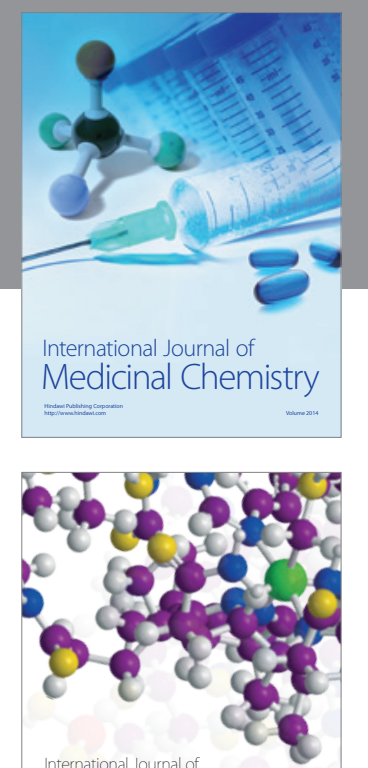

\section{Carbohydrate} Chemistry

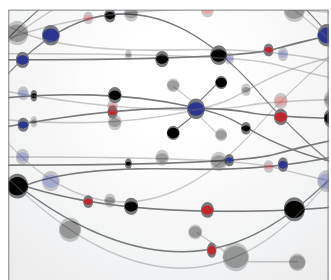

The Scientific World Journal
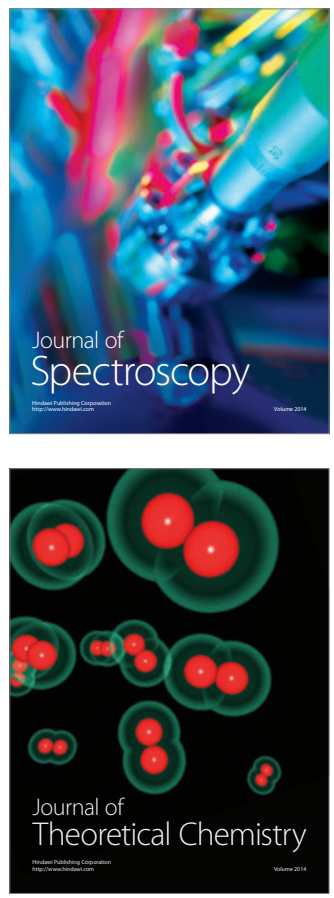
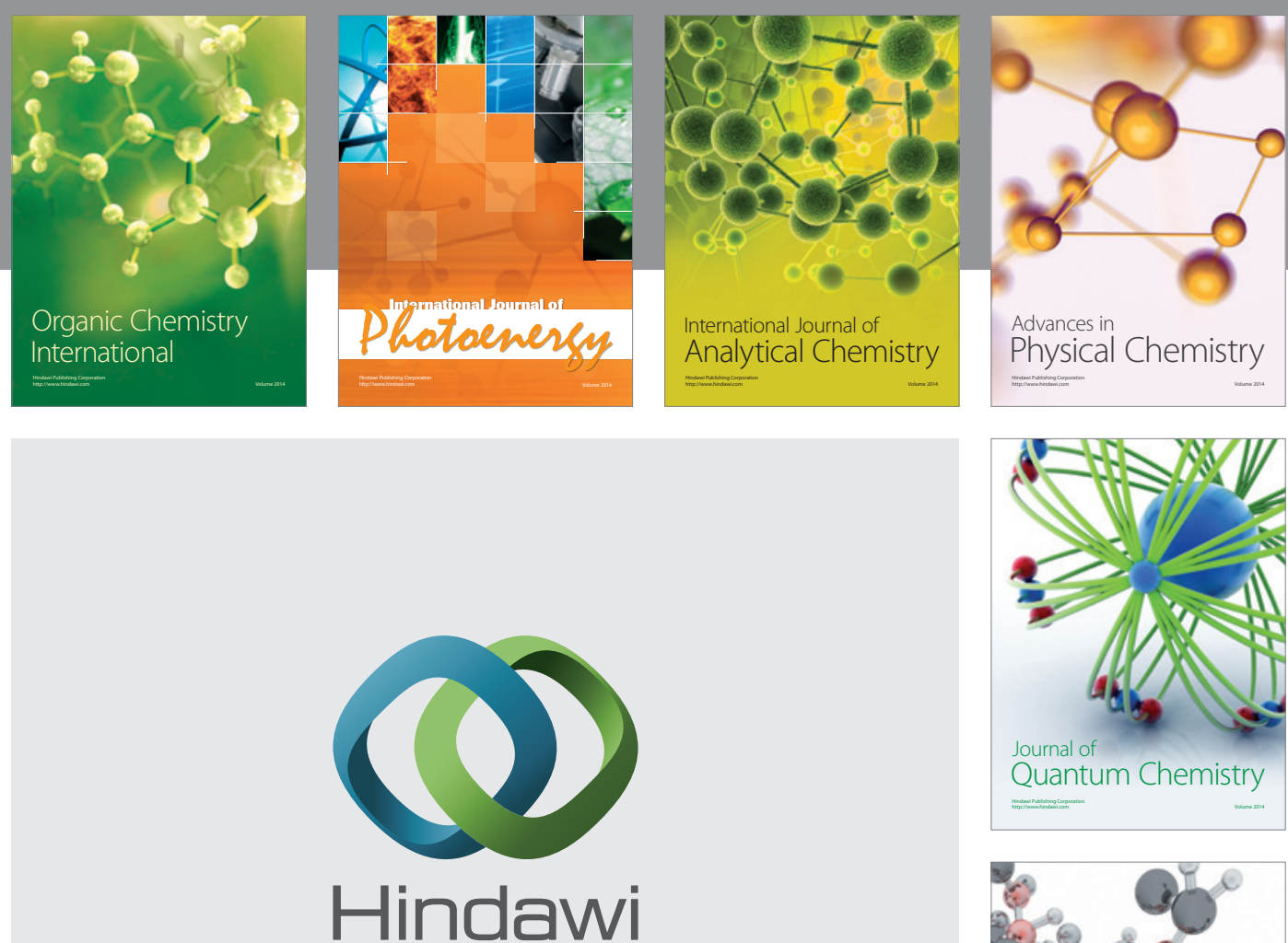

Submit your manuscripts at

http://www.hindawi.com

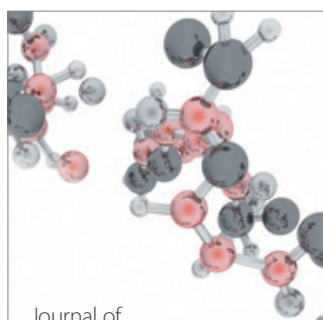

Analytical Methods

in Chemistry

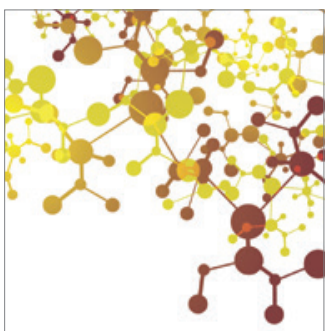

Journal of

Applied Chemistry

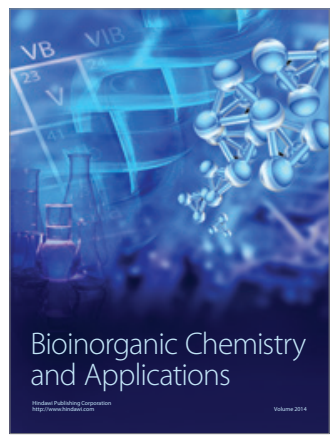

Inorganic Chemistry
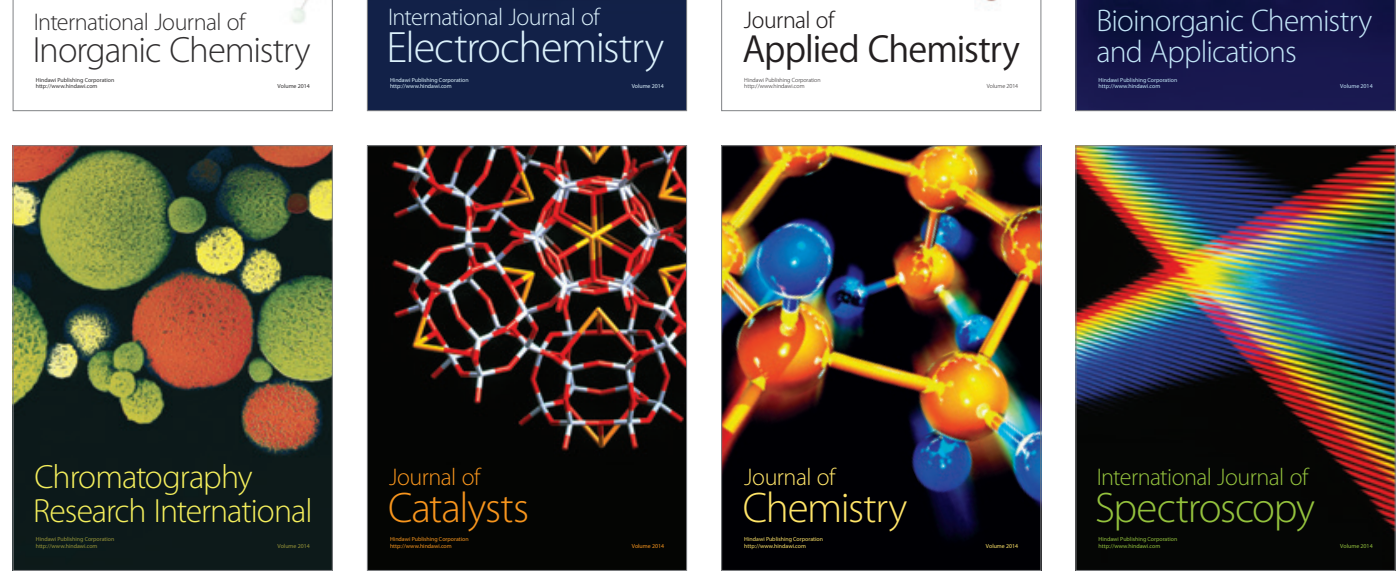